\title{
Exploring the Quality of Communication Between Patients with Psoriatic Arthritis and Physicians: Results of a Global Online Survey
}

\author{
Laura C. Coates · Valderilio F. Azevedo · Joseph C. Cappelleri · \\ Jade Moser $\cdot$ Lihi Eder $\cdot$ Pascal Richette $\cdot$ Meng-Yu Weng . \\ Ruben Queiro Silva · Amit Garg · Amar Majjhoo · Christopher E. M. Griffiths • \\ Pamela Young $\cdot$ Samantha Howland
}

Received: May 25, 2021 / Accepted: August 26, 2021 / Published online: September 27, 2021

(c) The Author(s) 2021

\section{ABSTRACT}

Introduction: Effective communication between patients with psoriatic arthritis (PsA) and their physicians is important for optimizing

Supplementary Information The online version contains supplementary material available at https:// doi.org/10.1007/s40744-021-00367-z.

L. C. Coates

Nuffield Department of Orthopaedics,

Rheumatology and Musculoskeletal Sciences,

University of Oxford, Oxford, UK

V. F. Azevedo

Universidade Federal do Paraná, Curitiba, Brazil

J. C. Cappelleri

Pfizer Inc, Groton, CT, USA

J. Moser

The Harris Poll, Rochester, NY, USA

L. Eder

Women's College Research Institute, University of

Toronto, Toronto, ON, Canada

P. Richette

Rheumatology Department, Lariboisière Hospital, Lariboisière, University of Paris, Paris, France

M.-Y. Weng

Department of Internal Medicine, Division of

Allergy, Immunology, and Rheumatology, National

Cheng Kung University Hospital, College of

Medicine, National Cheng Kung University, Tainan,

Taiwan treatment outcomes. We assessed the quality of patient-physician communication in terms of awareness and impact of PsA symptoms, their levels of satisfaction, and their perceptions of communications.

Methods: A global online survey was conducted by The Harris Poll in adult patients with PsA and physicians managing patients with PsA in eight countries. Participating physicians were either rheumatologists or dermatologists

R. Q. Silva

Rheumatology Division, HUCA, Oviedo, Spain

A. Garg

Donald and Barbara Zucker School of Medicine at Hofstra/Northwell, Hempstead, NY, USA

A. Majjhoo

Shores Rheumatology, St Clair Shores, MI, USA

C. E. M. Griffiths

Dermatology Centre, NIHR Manchester Biomedical

Research Centre, University of Manchester,

Manchester, UK

P. Young

Pfizer Inc, Collegeville, PA, USA

S. Howland $(\square)$

Pfizer Ltd, Walton Oaks, Tadworth, Surrey KT20

7NS, UK

e-mail: samantha.howland@pfizer.com 
seeing $\geq 10$ and $\geq 5$ patients with PsA per month, respectively. Patient and physician groups were unmatched. Patient-physician communication was assessed with 35-60 questions regarding discussion topics during consultations, levels of satisfaction with communication, and specific communication issues.

Results: A total of 1286 patients with PsA (983 and 303 whose primary treating physician was a rheumatologist or dermatologist, respectively) and 1553 physicians (795 rheumatologists and 758 dermatologists) completed the survey. Regardless of whether they were primarily treated by a rheumatologist or dermatologist, most patients reported a social $(84 \%$ and $81 \%$, respectively) or work ( $81 \%$ and $80 \%$, respectively) impact of PsA, and a major/moderate negative impact on their physical activity levels (79\% and $74 \%$, respectively) or emotional/mental wellbeing $(69 \%$ and $68 \%$, respectively). Physician responses were generally consistent with this; however, physicians often appeared to under-recognize the extent to which PsA affects patients. Most ( $\geq 85 \%)$ patients and physicians were very/somewhat satisfied with their patient-physician communication, and most $(\geq 86 \%)$ patients were comfortable raising their concerns/fears with their physician. However, $>40 \%$ of patients were identified as being at risk of suboptimal communication. These patients were significantly less likely to report their PsA symptoms even when asked, were less comfortable discussing the impacts of PsA with their physician, and were more likely to experience major/moderate impacts of PsA on their healthrelated quality of life (HRQoL).

Conclusions: Physicians often underestimate the impacts of PsA, compared with patients, and some patients may be at risk of suboptimal communication with their attending physician, which may worsen the HRQoL impacts of PsA. These findings highlight a need for ways to improve communication between patients with PsA and their healthcare providers.

\section{PLAIN LANGUAGE SUMMARY}

Psoriatic arthritis (PsA) is a disease that can cause swollen and painful joints, as well as skin psoriasis. To effectively treat PsA, it is important that doctors and patients communicate well. We used a survey to ask patients with PsA and doctors from around the world about their communications about PsA. We also asked how PsA affects patients' quality of life. In total, 1286 patients and 1553 doctors took the survey. Most patients said that PsA affected their social and work lives. Similarly, PsA had a negative impact on physical activity and on emotional and/or mental wellbeing in most patients who answered the survey. Doctors answered similarly, but they were generally less likely to recognize how severely PsA can impact patients, compared with patients themselves. Most patients and doctors were happy with their patient-doctor communication, and most patients felt comfortable talking about their worries and/or fears with their doctor. However, some patients (about four out of 10) felt that communication with their doctors was not good; these patients were less likely/comfortable to talk about their PsA symptoms and the impacts of PsA with their doctor. PsA was also more likely to negatively impact these patients' quality of life. This survey shows that it is important to find ways to improve communication between patients with PsA and their doctors.

Keywords: Communication; Health-related quality of life; Patients; Physicians; Psoriatic arthritis; Surveys and questionnaires 


\section{Key Summary Points}

\section{Why carry out this study?}

Effective management of psoriatic arthritis (PsA) depends on shared decision-making between physicians and patients.

Therefore, communication between patients with PsA and their physician is critical in order to optimize patient care and for the success of treat-to-target strategies.

This study utilized a global online survey of patients with PsA $(N=1286)$, and rheumatologists $(N=795)$ and dermatologists $(N=758)$ managing patients with PsA to determine the impact of PsA on daily life from the perspective of patients and physicians.

\section{What was learned from the study?}

Most patients reported that PsA had a major or moderate impact on their work and social lives, physical activity level, and emotional wellbeing; physicians often underestimated the impact that PsA has on their patients.

Although communications between patients with PsA and physicians were generally good, those patients who had suboptimal communications with their treating physicians were less likely to discuss the impact of the PsA symptoms and more likely to experience their major negative impacts.

These findings highlight an unmet need for ways to help improve communication and facilitate shared decision-making between patients and their healthcare professional.

\section{INTRODUCTION}

Psoriatic arthritis (PsA) is a chronic, immunemediated inflammatory disease with musculoskeletal (e.g., peripheral arthritis, dactylitis, enthesitis, and spondylitis) and dermatologic (e.g., skin and nail psoriasis) manifestations $[1,2]$. Both the physical symptoms and psychologic effects of PsA can negatively impact patients' health-related quality of life (HRQoL) and work productivity [3]. As patients consider pain, fatigue, skin problems, and the ability to carry out work/leisure activities to be the most important domains affected by PsA [4], improving these domains is therefore a priority of treatment.

An overarching principle for the management of PsA is shared decision-making between physicians and patients [5]. Effective communication between patients with PsA and their physicians is therefore important for optimizing patient care and for the success of treat-to-target approaches [5]. For example, misalignment between patients and physicians with regards to their satisfaction with PsA control has been associated with increased disease activity and disability, with these patients reporting more swollen and tender joints, greater work impairment, and higher disease burden than patients where patient/physician satisfaction was aligned [6]. Improving patient-physician communication has been proposed as a solution to this misalignment by helping patients with PsA express their feelings about the impact of their symptoms on daily life [7].

A global online survey of patients with PsA, and rheumatologists and dermatologists managing patients with PsA, was conducted by The Harris Poll to determine the impact of PsA on daily life from the perspective of patients and physicians. The overall findings of the survey from the patient's perspective have been reported previously [8]. In this analysis, data from the survey were used to assess patient-physician communication in terms of: (1) PsA symptoms and impact according to patients and physicians; (2) patients' perceptions of their communication with their physicians; (3) communication from the physician's 
perspective, investigating their awareness of the impact of PsA on their patients' HRQoL and their patients' concerns and fears; and (4) the impact of suboptimal patient-physician communication on HRQoL.

\section{METHODS}

\section{Global Online Survey}

Data were collected via online patient and physician surveys conducted by The Harris Poll in Australia, Brazil, Canada, France, Spain, Taiwan, the UK, and the USA. The patient survey was conducted from November 2, 2017 to March 12, 2018 and the physician survey was conducted from December 11, 2017 to June 18, 2018. The physicians were not necessarily caring for any of the patient respondents included in the analysis.

Patients were recruited from online market research panels. Prospective respondents completed an initial screening survey to confirm eligibility. Participating patients were aged $\geq 18$ years, had a diagnosis of PsA, had been living with PsA for $>1$ year prior to participation, had received (previously or currently) $\geq 1$ disease-modifying antirheumatic drug (DMARD) for PsA, and had visited either a rheumatologist or dermatologist for PsA in the past 12 months. Participating physicians were licensed rheumatologists or dermatologists who had consultations with $\geq 10$ or $\geq 5$ patients with PsA per month, respectively. Physicians were recruited from online medical market research panels (panels vary by country). Medical specialty of prospective respondents was confirmed at the time of joining such panels. At least $50 \%$ of the patients treated by the rheumatologists and $\geq 35 \%$ ( $\geq 50 \%$ in the USA) of the patients treated by the dermatologists must have been receiving DMARDs or biologic DMARDs (bDMARDs). All eligible participants were required to provide consent to continue to the core survey content.

The surveys considered patients' and physicians' perspectives on PsA, including questions relating to demographics, disease characteristics, PsA impact, HRQoL, patient-physician communication, and treatment satisfaction. For each country, a custom set of demographic questions was followed by a dynamic number of core questions (approximately 35-60 questions in total), which varied depending on patient responses. No qualitative questions were included in the survey. Patients were recruited from online market research panels made up of members who agreed to participate in this type of research. Qualified respondents provided informed consent to complete the research. The surveys were non-interventional and were not conducted as a clinical study. All respondents agreed to participate but ethics approval was not required.

\section{Analyses Exploring Patient and Physician Communication and Perspectives}

Patient-reported patient-physician communication status was stratified based on their agreement or disagreement with each of the following two statements in the patient survey: Statement A: 'I worry that if I ask too many questions, my healthcare professional (HCP) will see me as a difficult patient and it will affect the quality of care I receive' and Statement B: 'I often tell my HCP I am fine when I am really experiencing symptoms'. These statements were identified by the steering committee for use as indicators of suboptimal communication. As such, patients who agreed with one or both statements were considered (and are hereafter referred to) as being at risk of suboptimal communication.

This analysis assessed patient and physician responses to the survey questions regarding demographics and disease characteristics, perceived impact of PsA on HRQoL, patient satisfaction with physician communication, perceived impact of suboptimal communication on patients' lives (including HRQoL), and their concerns and fears. All patient and physician survey questions included in this analysis are shown in Tables S1 and S2, respectively.

The impact of PsA on HRQoL was assessed by questions regarding the negative impacts of PsA, including social and work impacts, as described previously [8]. Patient-physician 
communication was assessed by questions regarding topics discussed during consultations, satisfaction with patient-physician communication, and specific communication issues. Patients' concerns and fears were assessed by questions regarding the aspects of PsA that concerned them most and the reasons they were not comfortable raising these concerns with their physician.

\section{Statistical Analyses}

Data were summarized descriptively. Differences between responses in the patient and physician surveys were analyzed using twotailed Chi-square tests for groups with $\geq 100$ patients. A $p$ value of $<0.05$ was considered to indicate statistical significance.

The unweighted sample sizes reflected the total number of patients who completed the survey. As data were collected from eight countries in total, a post-weight was applied to adjust for the relative size of each individual country's adult population within the total adult population (i.e., the total from all countries surveyed) [9]. All percentages reported were calculated and analyzed based on the weighted global total, hereafter referred to as the weighted base $\left(N_{w b}\right)$. For each question, data were selected for responders for whom either a rheumatologist or a dermatologist was mostly responsible for managing their PsA, with the aim being to capture patients who had, or were expecting to have, an enduring relationship with that particular specialty team. For statistical testing, the effective base was used, which takes into account the increased variability created by weighting and reduces the impact of weighting on the outcome of the statistical testing [9].

\section{RESULTS}

\section{Patients}

A total of 3405 patients received the survey. Of the 1286 patients who responded to the survey, $983(76 \%)$ reported that a rheumatologist was primarily responsible for managing their PsA, and 303 (24\%) reported that a dermatologist was primarily responsible (Table 1 ). The corresponding unweighted bases comprised 960 and 326 patients, respectively.

The overall demographics and disease characteristics of the patients have been described previously [8]. The two individual patient groups primarily treated by a rheumatologist or dermatologist were similar with regard to most demographics and disease characteristics, the exceptions being mean age and the proportions of patients residing in Brazil or the USA, or whose overall health was good or fair (Table 1). Most rheumatologist- or dermatologist-treated patients reported moderate/severe PsA (85\% and $80 \%$, respectively) and a majority reported poor/fair overall health $(68 \%$ and $58 \%$, respectively).

There were no major differences in characteristics between those patients who agreed or disagreed with either Statement A or B. Mean age and mean age at diagnosis were slightly lower in those who agreed (mean age, 36-40 years; mean age at diagnosis, $28-31$ years) vs. disagreed (mean age, 41-44 years, mean age at diagnosis, 31-35 years) with either statement. PsA medications and reported overall health were generally similar across those who agreed and disagreed with either statement; most patients reported poor/fair overall health (55-71\% and 55-65\% for those who agreed and disagreed with either statement, respectively). The percentage of female vs. male patients was consistent across groups.

\section{Physicians}

A total of 1890 physicians (930 rheumatologists; 960 dermatologists) received the survey. Of the 1553 physicians who completed the survey, 795 were rheumatologists and 758 were dermatologists. The mean number (standard deviation) of unique patients with PsA seen each month was 54 (70) for rheumatologists and 23 (24) for dermatologists. Few rheumatologists $(1 \%)$ or dermatologists $(<1 \%)$ described their patient population as pediatric. 
Table 1 Patient demographics and disease characteristics, as reported by patients treated by a rheumatologist or dermatologist

\begin{tabular}{|c|c|c|c|}
\hline & \multirow{2}{*}{$\begin{array}{l}\text { Total patients } \\
\left(N_{w b}=1286 / N=1286\right)\end{array}$} & \multicolumn{2}{|c|}{ Primary treating physician } \\
\hline & & $\begin{array}{l}\text { Rheumatologist } \\
\left(N_{w b}=983 / N=960\right)\end{array}$ & $\begin{array}{l}\text { Dermatologist } \\
\left(N_{w b}=303 / N=326\right)\end{array}$ \\
\hline \multicolumn{4}{|l|}{ Country, $n(\%)^{\mathrm{a}}$} \\
\hline Australia & $39(3)$ & $29(3)$ & $9(3)$ \\
\hline Brazil & $319(25)$ & $218(22)$ & $101\left(33^{*}\right)$ \\
\hline Canada & $62(5)$ & $43(4)$ & $19(6)$ \\
\hline France & $111(9)$ & $83(8)$ & $28(9)$ \\
\hline Spain & $85(7)$ & $60(6)$ & $25(8)$ \\
\hline Taiwan & $41(3)$ & $29(3)$ & $12(4)$ \\
\hline UK & $109(8)$ & $78(8)$ & $32(10)$ \\
\hline USA & $521(40)$ & $443\left(45^{*}\right)$ & $78(26)$ \\
\hline Age, years, mean (SD) & $41.2(13.3)$ & $41.9^{*}(12.8)$ & $38.9(14.6)$ \\
\hline Female, $n(\%)^{\mathrm{a}}$ & $674(52)$ & $532(54)$ & $142(47)$ \\
\hline \multicolumn{4}{|l|}{ Overall health, ${ }^{\mathrm{b}} n(\%)^{\mathrm{a}}$} \\
\hline Excellent & $57(4)$ & $38(4)$ & $19(6)$ \\
\hline Good & $388(30)$ & $279(28)$ & $109\left(36^{*}\right)$ \\
\hline Fair & $674(52)$ & $540\left(55^{*}\right)$ & $134(44)$ \\
\hline Poor & $167(13)$ & $126(13)$ & $41(13)$ \\
\hline Time since diagnosis, years, mean (SD) & $9.0(8.6)$ & $9.0(8.6)$ & $9.0(8.7)$ \\
\hline \multicolumn{4}{|l|}{ Current PsA disease severity, ${ }^{\mathrm{b}} n(\%)^{\mathrm{a}}$} \\
\hline Mild & $205(16)$ & $145(15)$ & $60(20)$ \\
\hline Moderate & $849(66)$ & $648(66)$ & $202(66)$ \\
\hline Severe & $232(18)$ & $190(19)$ & $42(14)$ \\
\hline \multicolumn{4}{|l|}{ Current PsA medication, $n(\%)^{\mathrm{a}}$} \\
\hline bDMARD only ${ }^{c}$ & $483(38)$ & $372(38)$ & $111(37)$ \\
\hline Oral DMARD only ${ }^{\mathrm{d}}$ & $419(33)$ & $331(34)$ & $88(29)$ \\
\hline Oral DMARD + bDMARD & $228(18)$ & $168(17)$ & $60(20)$ \\
\hline NSAIDs/steroids only & $140(11)$ & $100(10)$ & $40(13)$ \\
\hline Not sure & $6\left(^{(\mathrm{e})}\right.$ & $4\left(^{e}\right)$ & $2(1)$ \\
\hline
\end{tabular}


Table 1 continued

\section{Total patients \\ $\left(N_{w b}=1286 / N=1286\right)$}

Primary treating physician

Rheumatologist Dermatologist

$\left(N_{w b}=983 / N=960\right) \quad\left(N_{w b}=303 / N=326\right)$

$10(1)$

$7(1)$

$2(1)$

DDMARD biologic DMARD, DMARD disease-modifying antirheumatic drug, NSAID non-steroidal anti-inflammatory drug, $N$ unweighted sample size, i.e., total number of patients who responded to the question, $N_{w b}$ weighted base, i.e., total number of adult patients adjusted for the size of each country's adult population, $n$ number of patients with the characteristic, $P_{S} A$ psoriatic arthritis, $S D$ standard deviation

a Percentages were calculated based on the $N_{w b}$ as the denominator

b Current overall health and PsA disease severity were reported by patients

c bDMARD therapy varied by individual country but could include abatacept, adalimumab, certolizumab pegol, etanercept, golimumab, infliximab, secukinumab, or ustekinumab (patient questionnaire used brand names, rather than generic drug names)

d Oral DMARD therapy varied by individual country but could include apremilast, azathioprine, chloroquine, cyclosporine, hydroxychloroquine, leflunomide, methotrexate, or sulfasalazine

${ }^{\mathrm{e}}$ Indicates $<1 \%$ of patients

* Indicates a statistically significant $(p<0.05)$ difference between the rheumatologist- and dermatologist-treated patients

\section{Patient- and Physician-Reported Impact of PsA}

Regardless of whether they were primarily treated by a rheumatologist or dermatologist, most patients reported social $(84 \%$ and $81 \%$, respectively) or work $(81 \%$ and $80 \%$, respectively) impacts of PsA, most commonly emotional distress (60\% and 53\%, respectively) and taking a sick day (52\% and $40 \%$, respectively) (Fig. S1a). The proportion of patients perceived by physicians to have experienced social or work impacts of PsA generally appeared to be lower in the physician survey than that reported in the patient survey (Fig. S1a).

Most patients reported that PsA had a major or moderate negative impact on their level of physical activity $(\geq 74 \%)$ and emotional/mental wellbeing ( $\geq 68 \%$ ) (Fig. S1b). Data from the physician survey were generally consistent with these findings, although the proportions of patients for whom the physicians considered that PsA had a major or moderate negative impact on these aspects of life were generally numerically higher than reported by patients (Fig. S1b).

\section{Patient-Physician Communication}

According to both patients and physicians, topics related to PsA treatment/management, overall health, impacts on physical and daily activities, and symptoms were generally the most commonly discussed of the predetermined consultation discussion topics listed in the patient and physician surveys, whereas the impacts on relationships and family, and romantic relationships and intimacy, were the least frequently discussed (Fig. S2).

Most patients primarily treated by a rheumatologist $(89 \%)$ or a dermatologist $(85 \%)$ were very $(57 \%$ and $50 \%$, respectively) or somewhat (33\% and $35 \%$, respectively) satisfied with the communication with their physician regarding PsA (Table 2). Similarly, $88 \%$ of rheumatologists and $85 \%$ of dermatologists were very (both $26 \%)$ or somewhat $(61 \%$ and $60 \%$, respectively) satisfied with their current communication with patients.

However, based on their responses to Statements $\mathrm{A}$ and $\mathrm{B},>40 \%$ of patients were deemed as being at risk of suboptimal patient-physician communication. Among the patients whose primary treating physician was a 


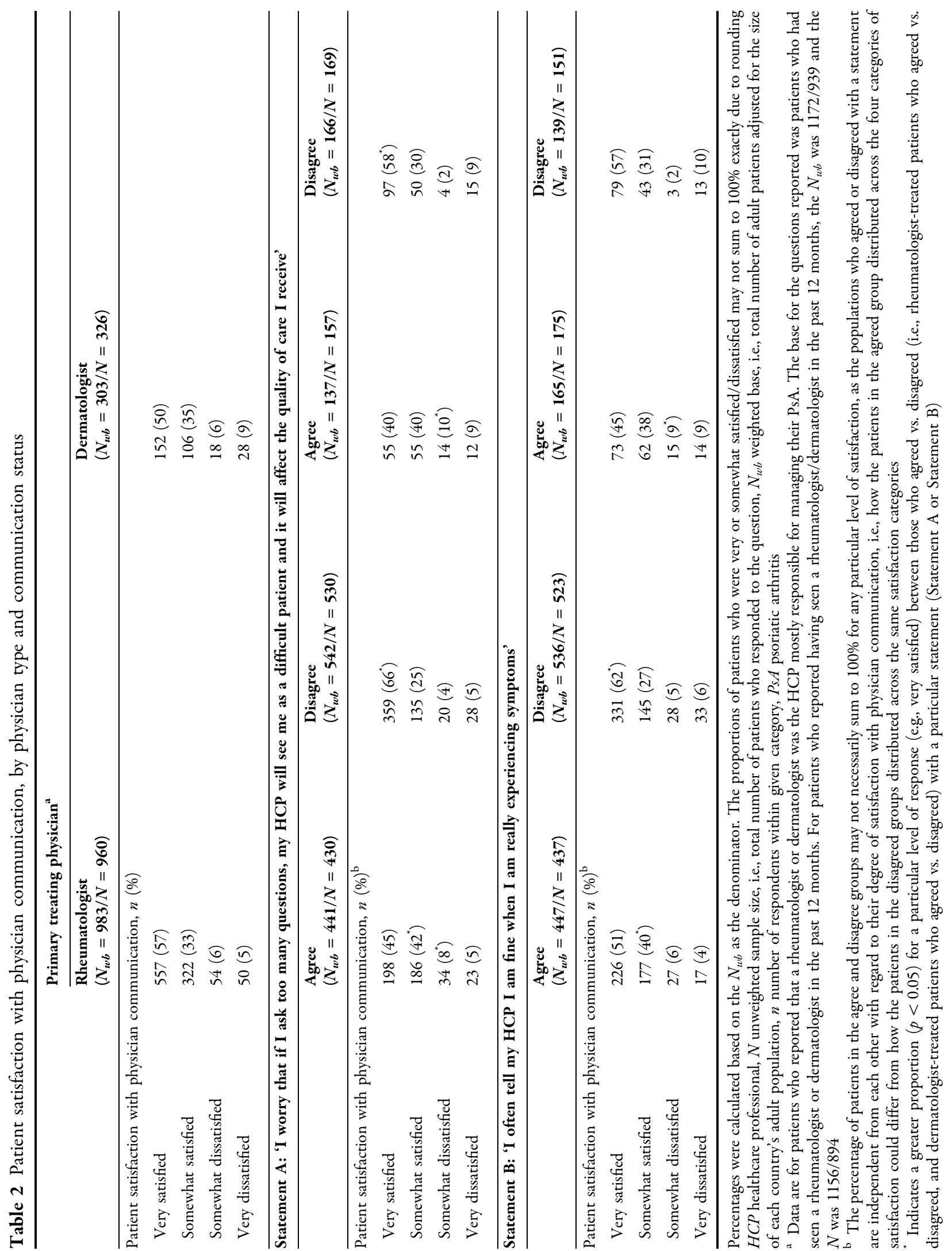


rheumatologist, 45\% agreed with Statement A ('I worry that if I ask too many questions, my HCP will see me as a difficult patient and it will affect the quality of care I receive'), $45 \%$ agreed with Statement B ('I often tell my HCP I am fine when I am really experiencing symptoms'), and $32 \%$ agreed with both statements. For those primarily treated by a dermatologist, $45 \%$ agreed with Statement A, 54\% agreed with Statement B, and 32\% agreed with both statements.

The proportions of patients who were 'very satisfied' with their current physician communication were generally significantly lower in patients categorized as at risk of suboptimal communication (i.e., those who agreed with Statement A or B) than in patients who disagreed with either statement. The one exception was among patients whose primary treating physician was a dermatologist, with the proportion of 'very satisfied' patients being numerically, but not significantly, lower in those who agreed with Statement B than in those who disagreed with Statement B (Table 2).

There were statistically significant differences $(p<0.05)$ between patients who agreed (i.e., were at risk of suboptimal communication) or disagreed with Statement A or Statement B in terms of specific areas of communication (Table 3). Compared with patients who disagreed with Statement A or Statement B, significantly greater proportions of patients who agreed with Statement A or Statement B also strongly or somewhat agreed that they wished they talked more about PsA and treatment goals with their physician, that they did not always proactively mention symptoms, and that they did not always mention symptoms even when asked. Compared with patients who disagreed with Statement A, significantly smaller proportions of patients who agreed with Statement A strongly or somewhat agreed that their physician was always willing to discuss medication concerns/alternative treatment plans, and that they were comfortable discussing impacts of PsA on daily living (Table 3).

In addition, among patients primarily treated by a rheumatologist, the proportion who strongly or somewhat agreed that they were comfortable raising their concerns and fears was also significantly smaller in those who agreed vs. those who disagreed with Statement A. Compared with patients who disagreed with Statement B, a significantly smaller proportion of patients whose primary treating physician was a rheumatologist and who agreed with Statement B also strongly or somewhat agreed that they were comfortable discussing the impacts of PsA on daily living. Compared with patients who disagreed with Statement B, a significantly smaller proportion of patients whose primary treating physician was a dermatologist and who agreed with Statement B strongly or somewhat agreed that they were comfortable raising their concerns or fears (Table 3).

Statistically significant differences $(p<0.05)$ were also evident between patients who agreed (i.e., were at risk of suboptimal communication) and those who disagreed with Statement A or Statement B in terms of the impact they felt PsA had on aspects of their HRQoL (Fig. 1).

Among patients treated primarily by a rheumatologist, significantly greater proportions of those who agreed vs. those who disagreed with Statement A or Statement B reported PsA had a major/moderate impact on their emotional/mental wellbeing, work productivity, career path, romantic relationships/ intimacy, relationship with friends/family, decision to start a family, and education (Fig. 1a). The proportion of patients who reported that PsA had a major/moderate impact on their level of physical activity and ability to perform certain activities was also significantly greater among patients who agreed vs. those who disagreed with Statement A. A broadly similar trend was observed among patients treated primarily by a dermatologist (Fig. 1b).

\section{Patient Worries and Fears Due to PsA}

The worries owing to PsA most commonly stated by patients were also amongst those most commonly noted as perceived patient worries by physicians (Fig. 2a); these included the effect of PsA on their ability to perform daily activities and/or live independently, concern that PsA symptoms would worsen, and fears of joint/ 


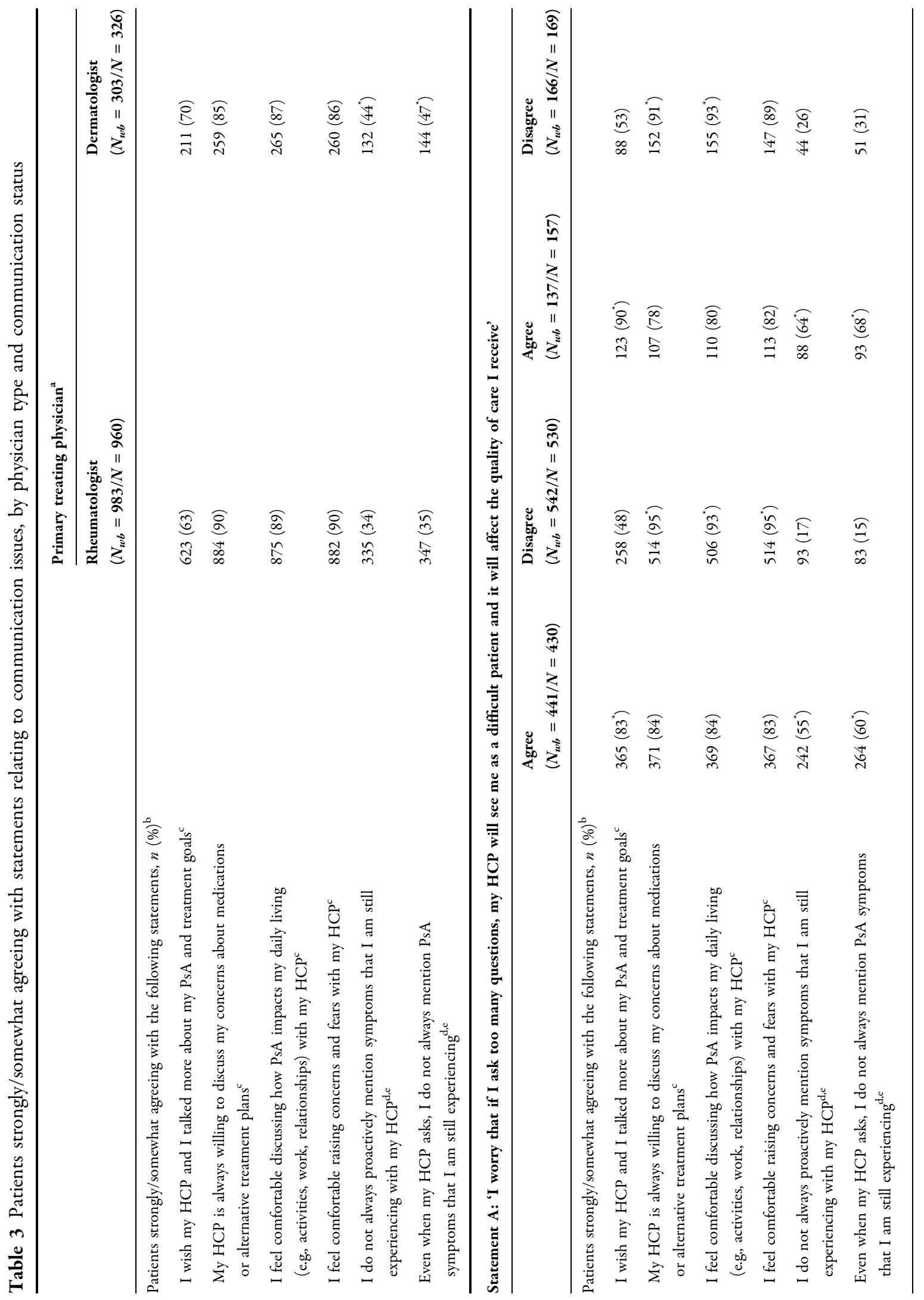




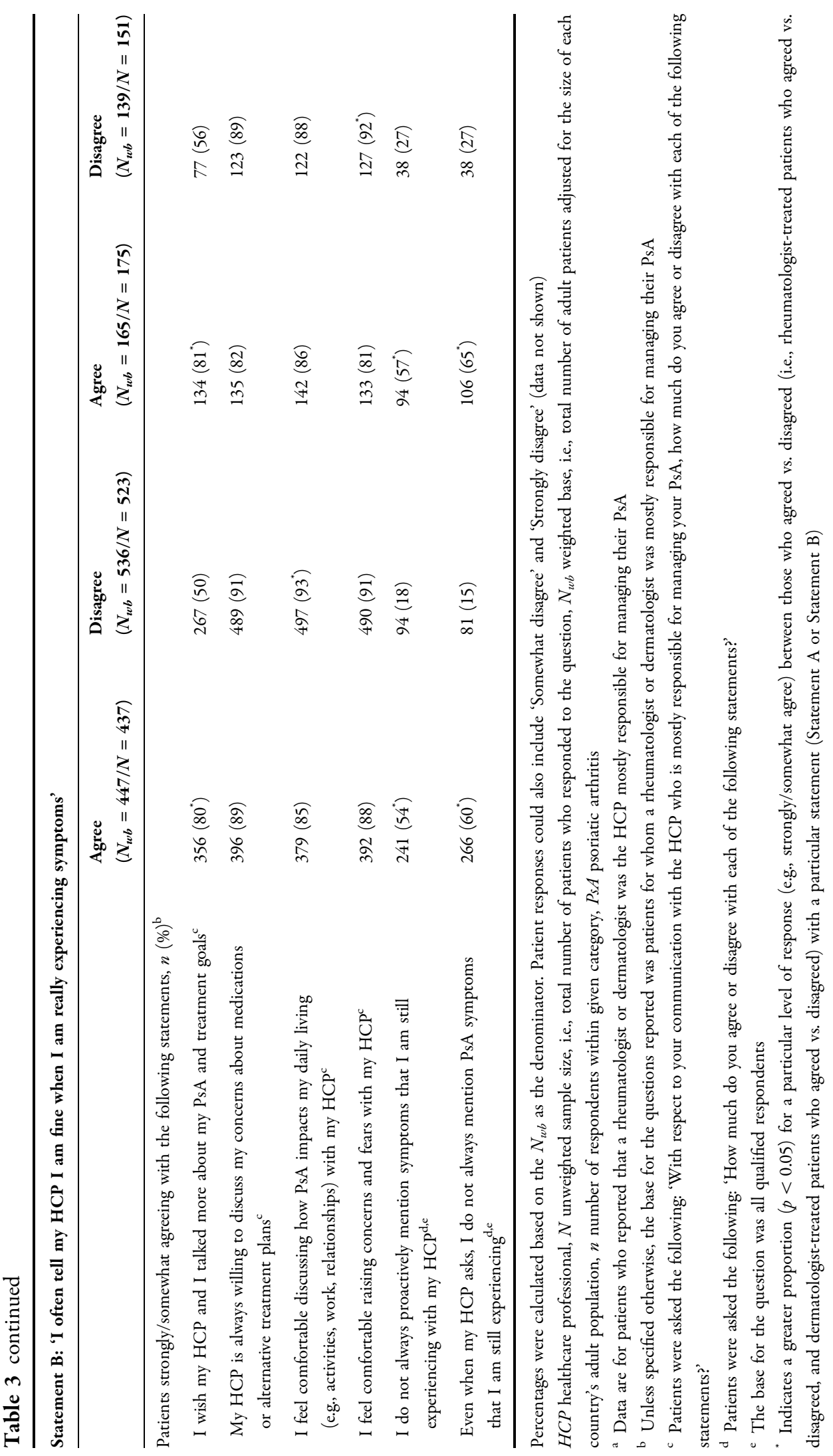


$\square$ Level of physical actvity

$\square$ Work productivity

$\square$ Relationship with friends/family $\square$ Ability to perform certain activities

$\square$ Career path

$\square$ Decision to start a family
Emotional/mental wellbeing

$\square$ Romantic relationships/intimacy

$\square$ Education

a

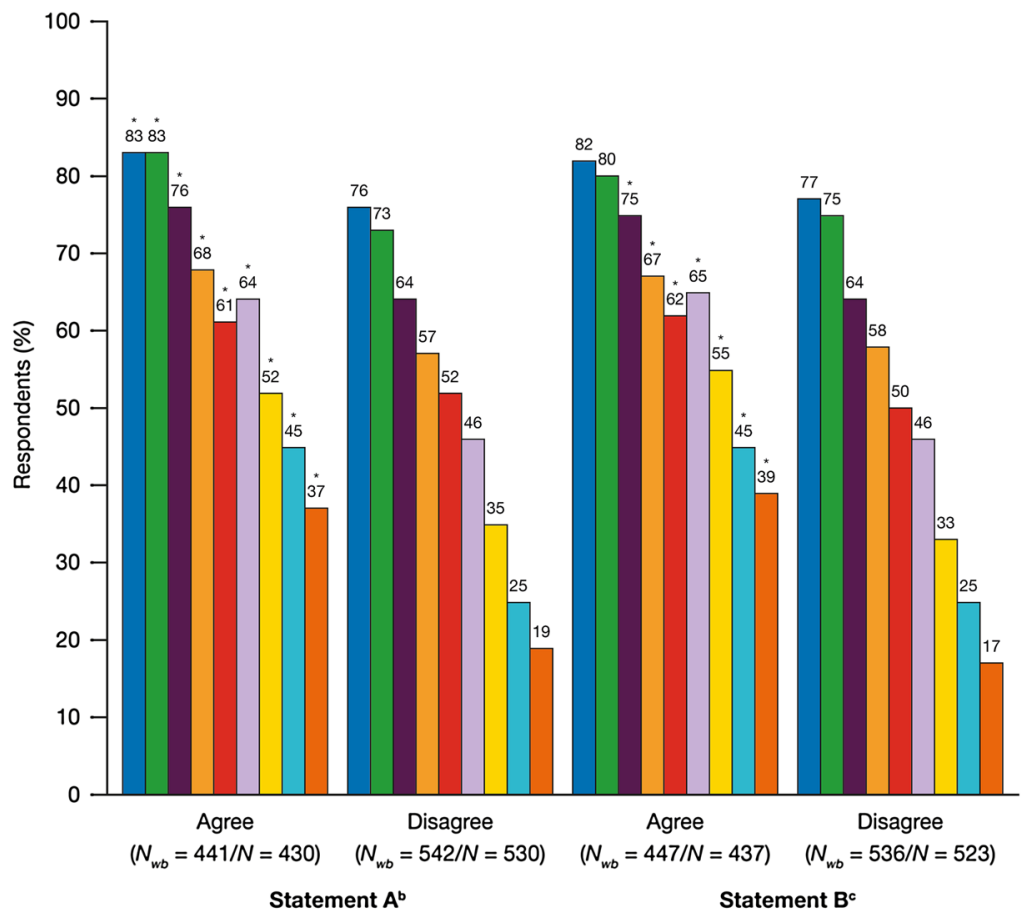

b

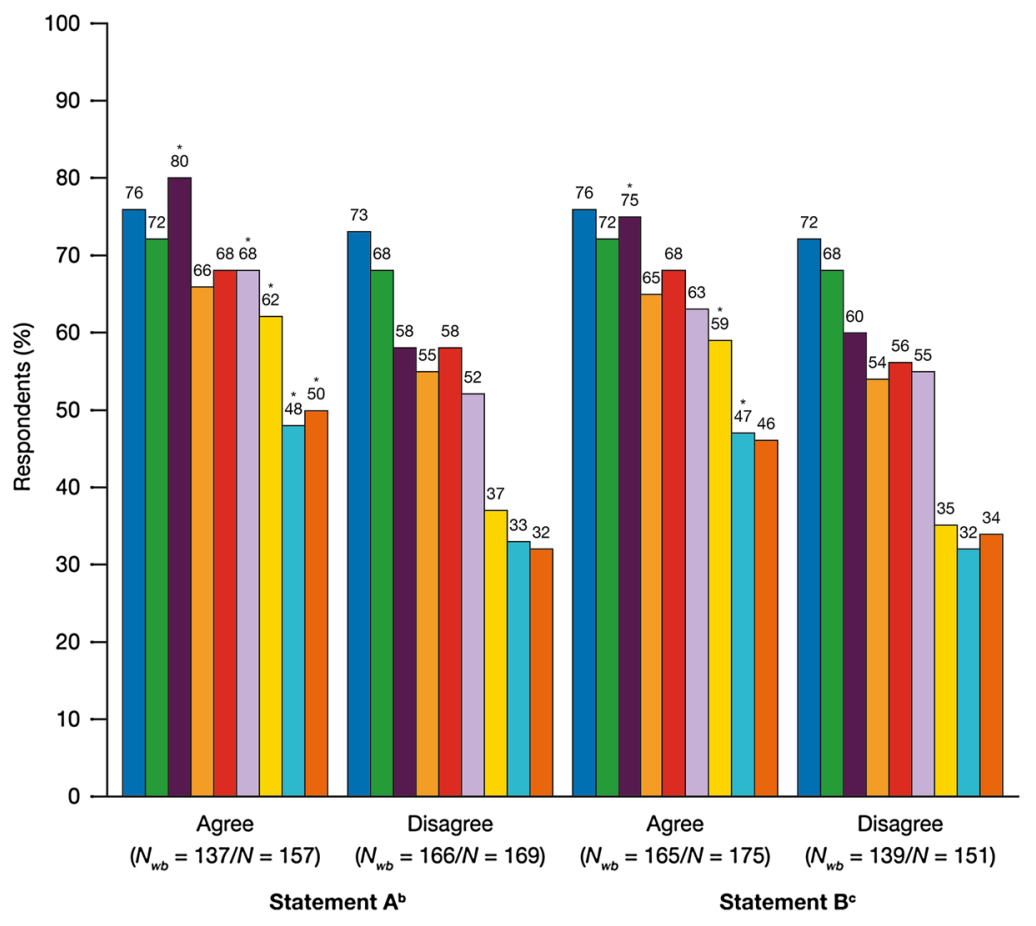


4 Fig. 1 Health-related quality of life impact ${ }^{a}$ of PsA by patient-physician communication status among patients treated by (a) a rheumatologist or (b) a dermatologist. Percentages were calculated based on the $N_{w b}$ as the denominator. The base for the question was all qualified respondents. $H C P$ healthcare professional, $N$ unweighted sample size, i.e., total number of patients who responded to the question, $N_{w b}$ weighted base, i.e., total number of adult patients adjusted for the size of each country's adult population, $P_{s} A$ psoriatic arthritis. ${ }^{\text {abased on patients }}$ indicating major or moderate impact in response to the following: 'How much of a negative impact, if any, has PsA had on each of the following aspects of your life?'. ${ }^{b}$ Statement A: I worry that if I ask too many questions my HCP will see me as a difficult patient and it will affect the

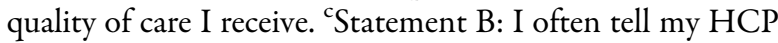
I am fine when I am really experiencing symptoms. "Indicates a greater response $(p<0.05)$ between those who agreed vs. disagreed with a particular statement (Statement A or Statement B)

spine damage. However, the proportions of physicians who recognized patient worries were generally numerically greater than the proportions of responders in the patient survey who reported these worries, except for 'children may develop PsA' (dermatologist data only), 'PsA medication will fail', 'exhaust all medication options for PsA', and 'PsA and/or other health conditions accompanying PsA may shorten life expectancy'.

Most patients strongly or somewhat agreed that they were comfortable raising their concerns and fears with their physician. Among those who did not strongly agree $\left(N_{w b}=467\right.$ [48\%] for patients primarily treated by a rheumatologist; $N_{w b}=156$ [51\%] for patients primarily treated by a dermatologist), the most common reasons cited were: the patient deferred to rheumatologist/dermatologist recommendations; the patient did not wish to be identified as being difficult; and worries that the rheumatologist/dermatologist would inform the patient that their treatment was failing (Fig. 2b).

\section{DISCUSSION}

The results of this global online survey highlight the breadth and depth of impact that PsA can have on wide-ranging aspects of patients' HRQoL and their perceptions of health. In general, there was agreement between responders to the patient and physician surveys about the impact of PsA, although physicians often appeared to under-recognize the frequency with which PsA affects patients in terms of social or work impact.

Consistent with the findings of a patientand physician-based global survey conducted in the rheumatoid arthritis setting [10], our results showed that most patients with PsA and physicians who treat patients with PsA were generally satisfied with patient-physician communication. However, $>40 \%$ of patient respondents with PsA appeared to be at risk of suboptimal communication with their physician, which has been shown to be associated with greater work impairment and higher disease burden in patients whose satisfaction with PsA control was misaligned with that of their physician [6]. Indeed, the findings of our analysis indicate that patients at risk of suboptimal communication are more likely to experience greater impacts of PsA on their HRQoL than other patients, and may therefore have greater healthcare needs.

Under-reporting of symptoms by patients may impact the treatment strategy recommended by physicians due to lack of information and could also affect the shared decisionmaking process that is important for the treatto-target approach. The need for continuous communication between patients and physicians to improve understanding and perceptions of disease severity and treatment goals/ options has been emphasized by the results of a USA population-based survey, in which the unmet needs of patients with psoriasis and/or PsA (including diagnosis, disease severity, therapy satisfaction, and undertreatment) were assessed [11]. Furthermore, although the intent of this work was not to compare the practices of different specialties, these may have contributed to the under-reporting of symptoms. 
a

$\square$ Rheumatologist patient-reported $\left(N_{\mathrm{wb}}=983 / \mathrm{N}=960\right) \square$ Dermatologist patient-reported $\left(N_{\mathrm{wb}}=303 / \mathrm{N}=326\right)$

$\square$ Rheumatologist-reported $\left(N_{\text {wo }}=795 / N=795\right)$

$\square$ Dermatologist-reported $\left(N_{w b}=758 / N=758\right)$ In this section

PsA will affect ability to perform activities of daily living and/or live independently

PsAVPA symptoms will not improve or might get worse

The damage PsA may be causing to joints/spine

Side effects from prescription medication(s) for PSA

PsA symptoms will never be under control

PsA will affect ability to work

Children may develop PsA

PsA medication will fail

Exhaust all medication options for PsA

PsA and/or other health conditions accompanying PsA may shorten life expectancy

Unable to afford treatment, or treatment will not be covered by insurance or healthcare system

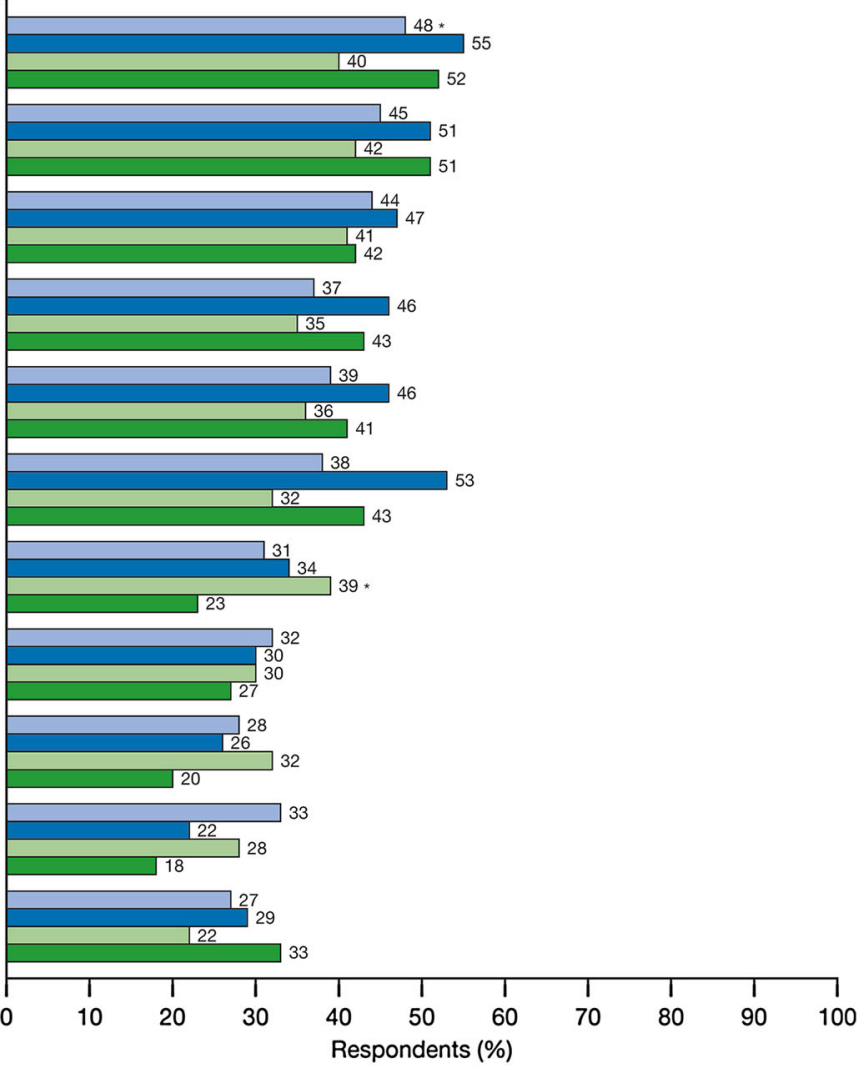

b

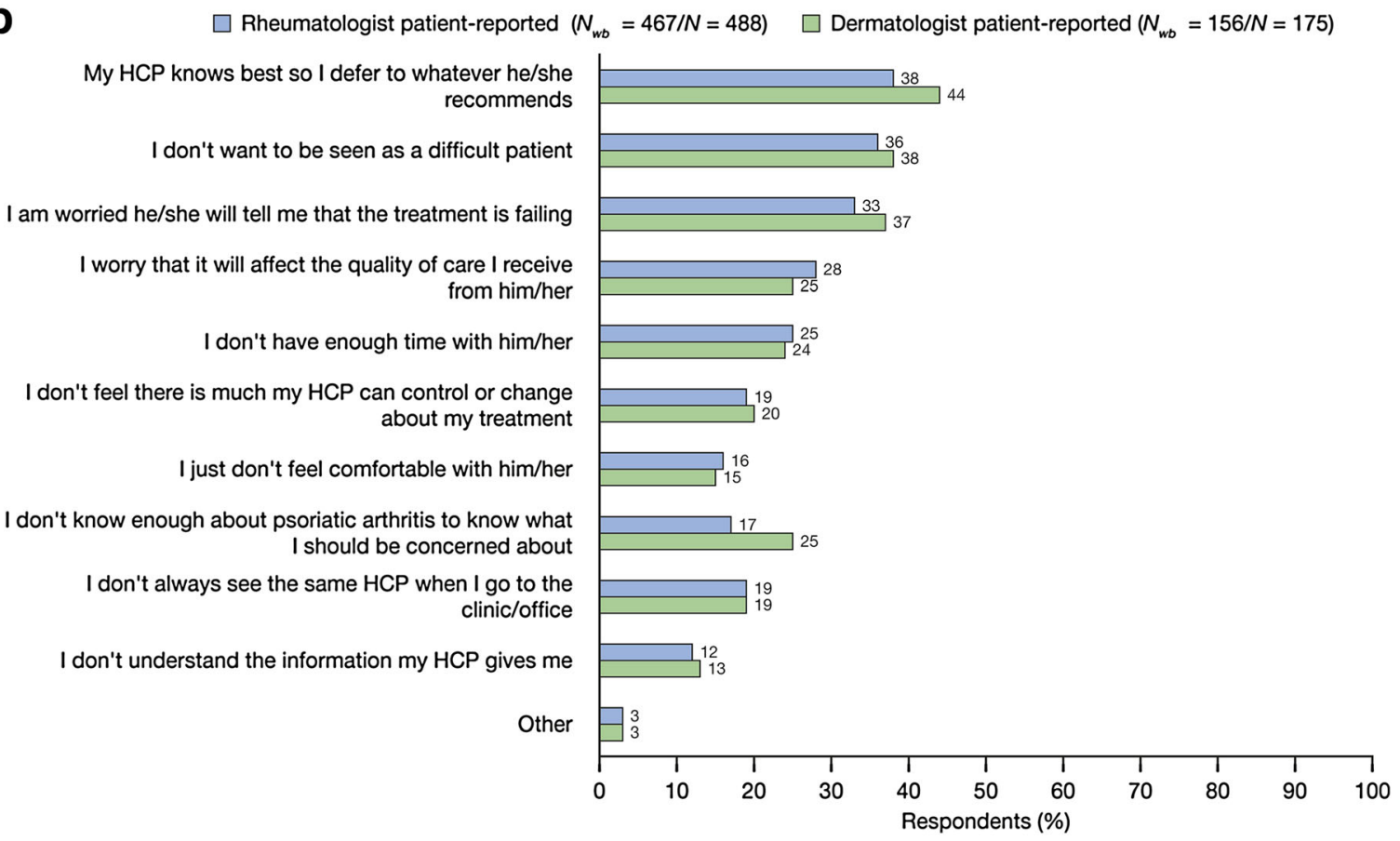


4Fig. 2 Communication of patient worries: a proportions of patients with worries, and physicians who reported their patients had these worries; and $\mathbf{b}$ patient-reported reasons for discomfort in raising concerns/fears with their physician. ${ }^{\text {a }}$ Percentages were calculated based on the $N_{w b}$ as the denominator. The base for all questions was all qualified respondents. Patient data are for patients who reported that a rheumatologist/dermatologist was mostly responsible for managing their PsA. For the proportion of patients with worries, and proportions of physicians who reported their patients had these worries, the response items reported are those for which the response rate was $>30 \%$ in any group. HCP healthcare professional, $N$ unweighted sample size, i.e., total number of patients who responded to the question, $N_{w b}$ weighted base, i.e., total number of adult patients adjusted for the size of each country's adult

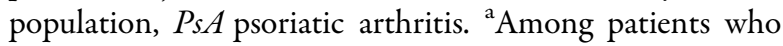
did not strongly agree with the statement, 'I feel comfortable raising concerns and fears with my HCP' (rheumatologist-treated patients, $N_{w b}=467$; dermatologist-treated patients, $N_{w b}=156$ ); patients could provide more than one response. Indicates a statistically significant $(p<0.05)$ difference between the rheumatologist- and dermatologist-treated patients

Rheumatologists and dermatologists will likely have focused on their respective areas of expertise, e.g., dermatologists may not routinely consider rheumatologic aspects of PsA; likewise, rheumatologists may not routinely consider dermatologic symptoms. Similarly, patients may not report symptoms that they consider irrelevant to that particular clinician.

It is possible that patients at risk of suboptimal communication relied on alternative sources of information and support regarding their disease, such as the Internet. We did not explore where these patients looked for information, but we propose that the Internet is a likely source. However, the Internet can be an inaccurate source of health information [12]; therefore, physicians should provide accurate information or help guide patients to accurate sources [13] that could aid the shared decisionmaking process.

A variety of other approaches may help to improve and maintain communication between patients with PsA and their physicians. For example, better educating patients about PsA via tailored interactive learning (e.g., written/multimedia material, phone calls, and online or face-to-face interactions) could enable them to communicate their concerns and expectations more clearly with their HCP $[14,15]$. Electronic tools, such as mobile apps, which enable patients to monitor disease activity using validated instrument measures, may make it easier for patients to share information and discuss their treatment progress with their physician [16-18]. Short appointment durations may also hinder communication [7]; patients should have access to specialist nurses trained in patient care and management, in line with European Alliance of Associations for Rheumatology (EULAR) guidelines [19]. Moreover, to enhance communication even during shorter appointments, tools could be developed to prepare patients ahead of consultations, as well as structured guidelines for consultations, including key questions for patients [7].

Limitations of this study included the separate administration of the survey to patients and to physicians who were not necessarily caring for any patient respondents included in the analysis. However, despite this lack of group matching (and consequently lack of a direct relationship between patient and physician data), the large sample sizes of the groups mean they can be considered representative. Also, the surveys relied upon the accurate recall of respondents, which was potentially more challenging for physicians than patients, given that patients were answering questions about themselves and were, therefore, more likely to have accurate recall vs. physicians, who were basing their responses on their own general impressions of the patients. Moreover, the proportion of physicians recognizing patient worries was often higher than patients reporting those worries; this discrepancy between patients and physicians' survey findings may reflect physicians making assumptions based on common patient worries, or may be a result of inaccurate physician recall.

Other limitations include the reliance of the surveys on accurate understanding of the questions, and that they did not include questions on comorbidities of PsA, such as fibromyalgia 
and/or mental health diagnoses. The quality of physician-patient communication regarding comorbidities would have been of interest, as consideration of comorbid conditions is recommended when caring for patients with PsA $[5,20]$. In addition, most patients reported their PsA severity as being moderate or severe, and almost two-thirds reported poor or fair overall health, potentially limiting the generalizability of the findings, as the degree to which patients communicate with their physician may be driven in part by the severity of their disease. This was recently demonstrated in a Scandinavian survey of patients with psoriasis and/or PsA in which the proportion of respondents who had discussed systemic treatments with a physician was shown to be greater among those who felt their symptoms were severe than among those who felt their symptoms were non-severe [21].

This analysis pooled data from eight countries, thus providing a global perspective. Evaluation of between-country differences was beyond the scope of this analysis, although it would be of interest, as cultural differences may influence the patient-physician relationship.

\section{CONCLUSIONS}

The results of this global survey suggest that some patients with PsA may be at risk of suboptimal communication, which could affect reporting of symptoms and the HRQoL impacts of PsA. In addition, physicians often underestimate the impacts of PsA, compared with patients. These findings highlight a need for ways to help improve communication and facilitate shared decision-making between patients and their HCP.

\section{ACKNOWLEDGEMENTS}

The authors would like to thank all the participants for completing the survey.

Funding. This study was sponsored by Pfizer Inc. Medical writing support was funded by Pfizer Inc. Pfizer Inc contributed to the conception/design of the study, data/statistical analyses, and data interpretation. The journal's Rapid Service Fee for this article was also funded by Pfizer Inc.

Authorship. All named authors meet the International Committee of Medical Journal Editors (ICMJE) criteria for authorship for this article, take responsibility for the integrity of the work as a whole, and have given their approval for this version to be published.

Authors' Contributions. All authors contributed to the interpretation of the data and critically revised each draft of the manuscript for intellectual content. Additionally, all named authors meet the International Committee of Medical Journal Editors (ICMJE) criteria for authorship for this article, take responsibility for the integrity of the work as a whole, and have given their approval for this version to be published.

Medical Writing, Editorial, and Other Assistance. Medical writing support, under the direction of the authors, was provided by Emma Deeks, PhD, and Mark Bennett, PhD, CMC Connect, McCann Health Medical Communications, with funding from Pfizer Inc, New York, NY, USA in accordance with Good Publication Practice (GPP3) guidelines (Ann Intern Med 2015; 163: 461-464).

Disclosures. Laura C. Coates has received grant/research support from AbbVie, Celgene, Janssen, Novartis, and Pfizer Inc, and is a consultant for AbbVie, Amgen, Biogen, Bristol-Myers Squibb, Celgene, Eli Lilly, Galapagos, Gilead, Janssen, Novartis, Pfizer Inc, and UCB. Valderilio F. Azevedo has received grant/research support from AbbVie and Pfizer Inc, is a consultant for AbbVie, Celltrion, Janssen, Novartis, Pfizer Inc, and Sandoz, and is on the speaker bureaus for AbbVie, Celltrion, Janssen, Novartis, Pfizer Inc, and Sandoz. Joseph C. Cappelleri is an employee of, and holds stock/stock options in, Pfizer Inc. Jade Moser is an employee of The Harris Poll. Lihi Eder has received grant/research support from AbbVie, is a consultant for AbbVie, Novartis, Pfizer Inc, and UCB, and is on 
the speaker bureaus for AbbVie, Amgen, Celgene, Novartis, and UCB. Pascal Richette has received consulting fees from AbbVie, Celgene, Eli Lilly, Janssen, MSD, Novartis, Pfizer Inc, and UCB. Meng-Yu Weng is a consultant and speaker for Eli Lilly, Janssen, Novartis, Pfizer Inc, and Roche. Ruben Queiro Silva has received grant/research support from AbbVie, Novartis, and Janssen, is a consultant for Janssen, Lilly, Novartis, and Pfizer Inc, and is on the speaker bureaus for AbbVie, Amgen, Janssen, Lilly, MSD, Novartis, and Pfizer Inc. Amit Garg is an advisor for AbbVie, Amgen, Boehringer Ingelheim, Incyte, Janssen, Novartis, Pfizer Inc, UCB, and Viela Bio, and has received research grants from AbbVie and the National Psoriasis Foundation. Amar Majjhoo has received grant/research support from AbbVie, Amgen, Janssen, and Novartis, is a consultant for AbbVie, Amgen, Celgene, Eli Lilly, Horizon Pharma, Novartis, and Pfizer Inc, and is on the speaker bureaus for AbbVie, Amgen, Bristol-Myers Squibb, Celgene, Eli Lilly, Horizon Pharma, Novartis, and Pfizer Inc. Christopher E.M. Griffiths has received grant/research support from AbbVie, Celgene, Eli Lilly, GSK, Janssen, LEO, Novartis, and Sandoz, and is a consultant for AbbVie, Almirall, Celgene, Eli Lilly, GSK, Janssen, LEO, Novartis, Pfizer Inc, Sun Pharmaceutical, and UCB. Pamela Young and Samantha Howland are employees of, and hold stock/stock options, in Pfizer Inc/Pfizer Ltd.

Compliance with Ethics Guidelines. Patients were recruited from online market research panels made up of members who agreed to participate in this type of research. Qualified respondents provided informed consent to complete the research. The surveys were non-interventional and were not conducted as a clinical study. All respondents agreed to participate but ethics approval was not required.

Data Availability. Upon request, and subject to certain criteria, conditions and exceptions (see https://www.pfizer.com/science/ clinical-trials/trial-data-and-results for more information), Pfizer will provide access to individual de-identified participant data from Pfizersponsored global interventional clinical studies conducted for medicines, vaccines, and medical devices (1) for indications that have been approved in the US and/or EU, or (2) in programs that have been terminated (i.e., development for all indications has been discontinued). Pfizer will also consider requests for the protocol, data dictionary, and statistical analysis plan. Data may be requested from Pfizer trials 24 months after study completion. The deidentified participant data will be made available to researchers whose proposals meet the research criteria and other conditions, and for which an exception does not apply, via a secure portal. To gain access, data requestors must enter into a data access agreement with Pfizer.

Prior Presentation. Data reported herein have been presented, in part, as poster presentations at the 5th Psoriasis and Psoriatic Arthritis Conference of the International Federation of Psoriasis Associations (2018), the 31st Annual French Congress of Rheumatology of the Societe Francaise de Rheumatologie (2018), the 2018 Annual Scientific Meeting of the American College of Rheumatology, and the 2018 Annual Meeting of the European League Against Rheumatism.

Open Access. This article is licensed under a Creative Commons Attribution-NonCommercial 4.0 International License, which permits any non-commercial use, sharing, adaptation, distribution and reproduction in any medium or format, as long as you give appropriate credit to the original author(s) and the source, provide a link to the Creative Commons licence, and indicate if changes were made. The images or other third party material in this article are included in the article's Creative Commons licence, unless indicated otherwise in a credit line to the material. If material is not included in the article's Creative Commons licence and your intended use is not permitted by statutory regulation or exceeds the permitted use, you will need to obtain permission directly from the copyright holder. To view a copy of this licence, visit http://creativecommons.org/licenses/by$\mathrm{nc} / 4.0 /$. 


\section{REFERENCES}

1. Ritchlin CT, Colbert RA, Gladman DD. Psoriatic arthritis. N Engl J Med. 2017;376:957-70.

2. Gladman DD, Antoni C, Mease P, Clegg DO, Nash P. Psoriatic arthritis: epidemiology, clinical features, course, and outcome. Ann Rheum Dis. 2005;64: ii14-7.

3. Gudu T, Gossec L. Quality of life in psoriatic arthritis. Expert Rev Clin Immunol. 2018;14: 405-17.

4. Gossec L, de Wit M, Kiltz U, et al. A patient-derived and patient-reported outcome measure for assessing psoriatic arthritis: elaboration and preliminary validation of the Psoriatic Arthritis Impact of Disease (PsAID) questionnaire, a 13-country EULAR initiative. Ann Rheum Dis. 2014;73:1012-9.

5. Gossec L, Baraliakos X, Kerschbaumer A, et al. EULAR recommendations for the management of psoriatic arthritis with pharmacological therapies: 2019 update. Ann Rheum Dis. 2020;79:700-12.

6. Furst DE, Tran M, Sullivan E, et al. Misalignment between physicians and patient satisfaction with psoriatic arthritis disease control. Clin Rheumatol. 2017;36:2045-54.

7. Garrido-Cumbrera M, Hillmann O, Mahapatra R, et al. Improving the management of psoriatic arthritis and axial spondyloarthritis: roundtable discussions with healthcare professionals and patients. Rheumatol Ther. 2017;4:219-31.

8. Coates LC, Orbai A-M, Azevedo VF, et al. Results of a global, patient-based survey assessing the impact of psoriatic arthritis discussed in the context of the Psoriatic Arthritis Impact of Disease (PsAID) questionnaire. Health Qual Life Outcomes. 2020;18:173.

9. Kish L. Survey sampling. New York: John Wiley and Sons; 1965.

10. Gibofsky A, Galloway J, Kekow J, et al. Comparison of patient and physician perspectives in the management of rheumatoid arthritis: results from global physician- and patient-based surveys. Health Qual Life Outcomes. 2018;16:211.

11. Lebwohl MG, Kavanaugh A, Armstrong AW, Van Voorhees AS. US perspectives in the management of psoriasis and psoriatic arthritis: patient and physician results from the population-based
Multinational Assessment of Psoriasis and Psoriatic Arthritis (MAPP) Survey. Am J Clin Dermatol. 2016;17:87-97.

12. Diaz JA, Griffith RA, Ng JJ, Reinert SE, Friedmann PD, Moulton AW. Patients' use of the Internet for medical information. J Gen Intern Med. 2002;17: $180-5$.

13. McMullan M. Patients using the Internet to obtain health information: how this affects the patienthealth professional relationship. Patient Educ Couns. 2006;63:24-8.

14. Zangi HA, Ndosi M, Adams J, et al. EULAR recommendations for patient education for people with inflammatory arthritis. Ann Rheum Dis. 2015;74: 954-62.

15. Gomez-Reino J, Orbai A-M, Gossec L. The patient's perspective on psoriatic arthritis: what more can rheumatologists do to optimise disease management? EMJ Rheumatol. 2017;4:50-7.

16. van Riel P, Alten $\mathrm{R}$, Combe $\mathrm{B}$, et al. Improving inflammatory arthritis management through tighter monitoring of patients and the use of innovative electronic tools. RMD Open. 2016;2:e000302.

17. Webers C, Beckers E, Boonen A, et al. Development, usability and acceptability of an integrated eHealth system for spondyloarthritis in the Netherlands (SpA-Net). RMD Open. 2019;5:e000860.

18. Kwan YH, Ong WJ, Xiong M, et al. Evaluation of mobile apps targeted at patients with spondyloarthritis for disease monitoring: systematic app search. JMIR Mhealth Uhealth. 2019;7:e14753.

19. van Eijk-Hustings $Y$, van Tubergen A, Boström C, et al. EULAR recommendations for the role of the nurse in the management of chronic inflammatory arthritis. Ann Rheum Dis. 2012;71:13-9.

20. Singh JA, Guyatt G, Ogdie A, et al. Special article: 2018 American College of Rheumatology/National Psoriasis Foundation guideline for the treatment of psoriatic arthritis. Arthritis Rhematol. 2019;71: 5-32.

21. Tveit KS, Duvetorp A, Østergaard M, et al. Treatment use and satisfaction among patients with psoriasis and psoriatic arthritis: results from the NORdic PAtient survey of Psoriasis and Psoriatic arthritis (NORPAPP). J Eur Acad Dermatol Venereol. 2019;33:340-54. 